\title{
Crystal structure of phenylpiperazinium tetrachlorozincate, $\left(\mathrm{C}_{10} \mathrm{H}_{16} \mathbf{N}_{2}\right)\left[\mathrm{ZnCl}_{4}\right]$
}

\author{
I. Ben Garbia, R. Kefi, A. Rayes and C. Ben Nasr* \\ Faculté des Sciences de Bizerte, Laboratoire de Chimie des Matériaux, 7021 Zarzouna Bizerte, Tunisia
}

Received March 14, 2005, accepted and available on-line May 24, 2005; CCDC no. 1267/1506
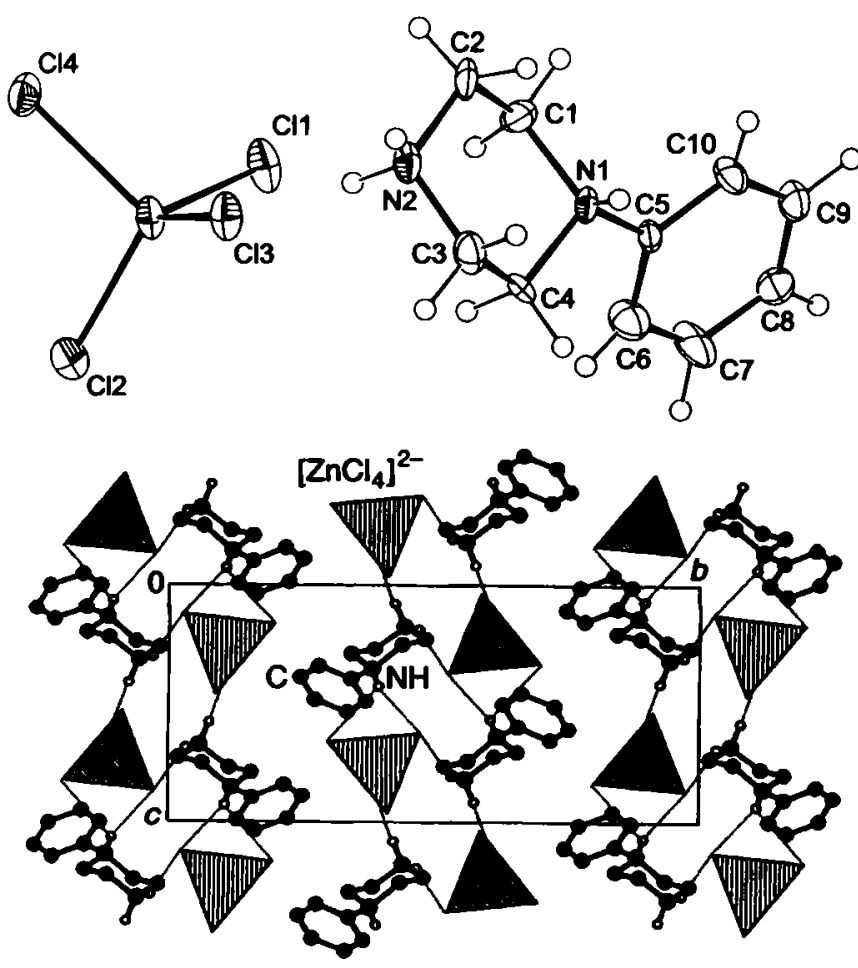

Abstract

$\mathrm{C}_{10} \mathrm{H}_{16} \mathrm{Cl}_{4} \mathrm{~N}_{2} \mathrm{Zn}$, monoclinic, $P 12_{1} / c 1$ (no. 14),

$a=7.768(3) \AA, b=20.393(3) \AA, c=9.615(6) \AA$,

$\beta=104.75(4)^{\circ}, V=1473.0 \AA^{3}, Z=4, R_{\mathrm{gt}}(F)=0.023$,

$w R_{\text {ref }}(F)=0.035, T=296 \mathrm{~K}$.

\section{Source of material}

Crystals of phenylpiperazinium tetrachlorozincate were prepared by slow evaporation of an aqueous solution of phenylpiperazine, hydrochloride acid and zinc chloride $(2: 2: 1)$. The obtained product was isolated by filtration and allowed to air-dry. The inorganic-organic hybrid compound crystals are stable for a longtime in normal conditions of temperature and humidity.

\section{Experimental details}

Due to the use of an incomplete data set of intensities, the expected accuracy of the bonding parameters could not be reached, e.g. $\sigma_{\text {average }}(\mathrm{N}-\mathrm{C})=0.004 \AA, \sigma_{\text {average }}(\mathrm{C}-\mathrm{C})=0.005 \AA$.

\section{Discussion}

The title inorganic-organic hybrid compound contains two basic components, the $\left[\mathrm{ZnCl}_{4}\right]^{2-}$ anion and the organic cation (figure, top). The phenylpiperazine amine (PHPIP) has two protonated ni-

\footnotetext{
* Correspondence author (e-mail: cherif.bennasr@fsb.mu.tn)
}

trogen atoms. So, the structure can be described by $\left[\mathrm{ZnCl}_{4}\right]$ units which form a hydrogen-bonded one-dimensional network with the phenylpiperazinium. The organic cation established both ionic interactions and strong hydrogen bonds with $\left[\mathrm{ZnCl}_{4}\right]^{2-}$ anions (N-H -..Cl: $3.099(3) \AA-3.318(3) \AA$ ) to built infinite chains located at $y=0$ and $1 / 2$ and spreading along the $c$ direction (figure, bottom). The van der Waals contacts between these chains give rise to a three-dimensional network in the structure and add stability to this compound.

In the [ $\left.\mathrm{ZnCl}_{4}\right]$ tetrahedra, the mean values of $\mathrm{Zn}-\mathrm{Cl}$ bond lengths and $\mathrm{Cl}-\mathrm{Zn}-\mathrm{Cl}$ angles of $2.273 \AA$ and $109.3^{\circ}$, respectively, are in agreement with those found in bis(2-amino-5-methylpyridinium) tetrachlorozincate $\left(2.270 \AA\right.$ and $109.4^{\circ}$, respectively) [1]. The nearest $\mathrm{Zn} \cdots \mathrm{Zn}$ intra-chain distance is $6.086 \AA$, while that between adjacent chains is $7.427 \AA$. The atoms C5, C6, $\mathrm{C7}, \mathrm{C8}, \mathrm{C9}$ and $\mathrm{ClO}$ of the phenyl ring of the title compound have a good planarity and they form a conjugated plane with average deviation of $0.0034 \AA$. The bond lengths of $\mathrm{C5}-\mathrm{C} 6, \mathrm{C} 5-\mathrm{Cl0}$, C6-C7, C7-C8, C8-C9 and $\mathrm{C} 9-\mathrm{C} 10$ are 1.353(3) $\AA$, $1.365(4) \AA, 1.390(5) \AA, 1.358(5) \AA, 1.370(5) \AA$ and $1.385(5) \AA$, respectively, which are between single bond and double bond and agree with that in benzene [2]. Furthermore, the distances $\mathrm{N} 1-\mathrm{C} 5, \mathrm{~N} 1-\mathrm{C} 1, \mathrm{~N} 1-\mathrm{C} 4, \mathrm{~N} 2-\mathrm{C} 2, \mathrm{~N} 2-\mathrm{C} 3, \mathrm{C} 1-\mathrm{C} 2$ and C3-C4 [1.491(4) $\AA, 1.513(4) \AA, 1.512(4) \AA, 1.483(4) \AA$, $1.479(4) \AA, 1.524(4) \AA$ and $1.508(4) \AA$, respectively] indicate single bonds. In this compound, $\mathrm{H} 6$ and $\mathrm{H} 7$ attached to the $\mathrm{N} 2$ nitrogen atom and $\mathrm{H} 1$ attached to $\mathrm{N} 1$ nitrogen atom play an important role in forming the molecular association through hydrogen bonding. Here two chlorine atoms, $\mathrm{Cll}$ and $\mathrm{Cl} 4$, act as acceptors of these $\mathrm{N}-\mathrm{H}$... Cl bonds. The other two chlorine atoms, $\mathrm{Cl} 2$ and $\mathrm{Cl} 3$, do not participate in the hydrogen bonding network.

The deviation from the perfect tetrahedral arrangement around $\mathrm{Zn}$ (II) in the title compound can be explained by involving of the chlorine ions in hydrogen bonding. In this complex, only the $\mathrm{Cl} 4$ atoms form two hydrogen bonds, which reduce the fractional charge on the $\mathrm{Cl} 4$ atom and lead to an elongation of $\mathrm{Zn}-\mathrm{Cl} 4$ bond by $0.06 \AA$ compared to that of $\mathrm{Zn}-\mathrm{Cl1}$ bond. Since $\mathrm{Cl} 2$ and $\mathrm{Cl} 3$ atoms do not participate in the hydrogen bonding, the electrostatic repulsions between $\mathrm{Cl} 2$ and $\mathrm{Cl} 3$ atoms are more pronounced resulting in the opening up of the $\mathrm{Cl} 2-\mathrm{Zn}-\mathrm{Cl} 3$ angle to $116.82(4)^{\circ}$ and in a comparatively larger deviation from the perfect tetrahedral arrangement around Zn(II). Similar features have been also observed in the structure of (benzotriazole) $2\left[\mathrm{CoCl}_{4}\right]$ [3], where only two chlorine atoms are engaged in the hydrogen bonding network causing an elongation of the $\mathrm{Co}-\mathrm{Cl}$ bonds by $0.06 \AA$ and opening up the $\mathrm{Cl}-\mathrm{Co}-\mathrm{Cl}$ angle involving the other two non-hydrogen bonded chlorine atoms. Thus, in this latter compound, the hydrogen bonding network and the deviation from ideal tetrahedral arrangement are comparable to those of the title compound. 
Table 1. Data collection and handling.

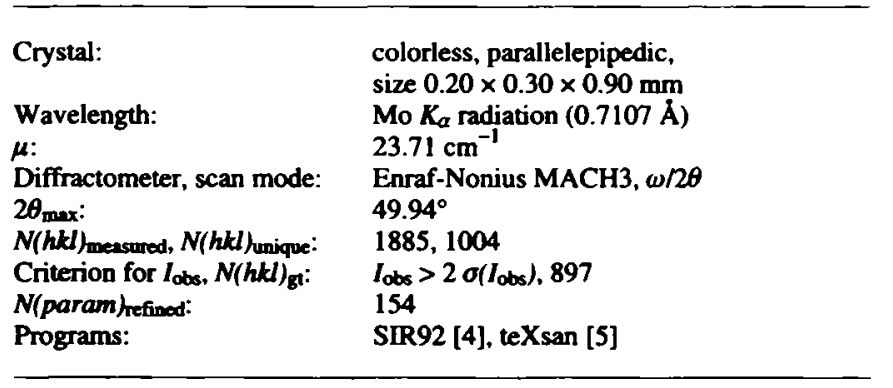

Table 2. Atomic coordinates and displacement parameters (in $\AA^{2}$ ).

\begin{tabular}{|c|c|c|c|c|c|}
\hline Atom & Site & $x$ & $y$ & $z$ & $U_{\text {iso }}$ \\
\hline$H(1)$ & $4 e$ & -0.2814 & -0.1058 & -0.0701 & 0.032 \\
\hline $\mathbf{H}(2)$ & $4 e$ & -0.5097 & -0.0884 & -0.3294 & 0.031 \\
\hline H(3) & $4 e$ & -0.5182 & -0.0339 & -0.2015 & 0.032 \\
\hline H(4) & $4 e$ & -0.2473 & -0.0087 & -0.1677 & 0.032 \\
\hline$H(5)$ & $4 e$ & -0.3459 & 0.0134 & -0.3388 & 0.025 \\
\hline H(6) & $4 e$ & -0.2295 & -0.0755 & -0.4184 & 0.063 \\
\hline $\mathbf{H}(7)$ & $4 e$ & -0.0804 & -0.0312 & -0.3083 & 0.032 \\
\hline H(8) & $4 e$ & -0.0235 & -0.0963 & -0.1397 & 0.022 \\
\hline H(9) & $4 e$ & -0.0143 & -0.1410 & -0.2733 & 0.030 \\
\hline $\mathbf{H}(10)$ & $4 e$ & -0.3014 & -0.1758 & -0.3021 & 0.032 \\
\hline H(11) & $4 e$ & -0.1976 & -0.1936 & -0.1446 & 0.028 \\
\hline$H(12)$ & $4 e$ & $-0.47 \% 2$ & $-0.238 i$ & -0.1593 & 0.032 \\
\hline H(13) & $4 e$ & -0.7007 & -0.2982 & -0.1426 & 0.021 \\
\hline H(14) & $4 e$ & -0.8570 & -0.2510 & 0.0159 & 0.041 \\
\hline $\mathbf{H}(15)$ & $4 e$ & -0.7772 & -0.1448 & 0.1075 & 0.049 \\
\hline H(16) & $4 e$ & -0.5499 & -0.0891 & 0.0370 & 0.016 \\
\hline
\end{tabular}

Table 3. Atomic coordinates and displacement parameters (in $\AA^{2}$ ).

\begin{tabular}{|c|c|c|c|c|c|c|c|c|c|c|}
\hline Atom & Site & $x$ & $y$ & $z$ & $U_{11}$ & $U_{22}$ & $U_{33}$ & $U_{12}$ & $U_{13}$ & $U_{23}$ \\
\hline $\mathrm{Zn}(1)$ & $4 e$ & $-0.14176(3)$ & $-0.11119(2)$ & $0.29117(3)$ & $0.0344(1)$ & $0.0439(4)$ & $0.0195(3)$ & $0.0001(1)$ & $0.0109(1)$ & $-0.0000(2)$ \\
\hline $\mathrm{Cl}(1)$ & $4 e$ & $-0.38399(6)$ & $-0.10851(3)$ & $0.38281(8)$ & $0.0327(2)$ & $0.0714(8)$ & $0.0270(6)$ & $-0.0038(3)$ & $0.0129(2)$ & $-0.0066(4)$ \\
\hline $\mathrm{Cl}(2)$ & $4 e$ & $-0.12870(7)$ & $-0.20110(4)$ & $0.16264(7)$ & $0.0520(3)$ & $0.0408(7)$ & $0.0352(6)$ & $0.0013(3)$ & $0.0167(3)$ & $-0.0045(4)$ \\
\hline $\mathrm{Cl}(3)$ & $4 e$ & $0.10175(6)$ & $-0.08720(4)$ & $0.46918(7)$ & $0.0330(2)$ & $0.0562(7)$ & $0.0219(5)$ & $-0.0015(3)$ & $0.0070(2)$ & $0.0006(4)$ \\
\hline $\mathrm{Cl}(4)$ & $4 e$ & $-0.17835(6)$ & $-0.02577(4)$ & $0.12472(7)$ & $0.0462(2)$ & $0.0398(7)$ & $0.0218(6)$ & $-0.0057(3)$ & $0.0051(3)$ & $0.0034(4)$ \\
\hline$N(1)$ & $4 e$ & $-0.3687(2)$ & $-0.11762(9)$ & $-0.1420(2)$ & $0.0300(7)$ & $0.029(2)$ & $0.015(2)$ & $-0.0029(8)$ & $0.0103(7)$ & $0.003(1)$ \\
\hline$N(2)$ & $4 e$ & $-0.1655(2)$ & $-0.0573(1)$ & $-0.3214(2)$ & $0.0356(7)$ & $0.037(2)$ & $0.022(2)$ & $-0.0055(9)$ & $0.0141(8)$ & $0.001(1)$ \\
\hline$C(1)$ & $4 e$ & $-0.4446(2)$ & $-0.0626(1)$ & $-0.2450(3)$ & $0.0352(9)$ & $0.024(2)$ & $0.035(2)$ & $0.003(1)$ & $0.013(1)$ & $0.007(2)$ \\
\hline$C(2)$ & $4 e$ & $-0.2957(3)$ & $-0.0182(1)$ & $-0.2671(3)$ & $0.0454(9)$ & $0.044(3)$ & $0.019(2)$ & $0.007(1)$ & $0.019(1)$ & $0.009(2)$ \\
\hline$C(3)$ & $4 e$ & $-0.0944(3)$ & $-0.1136(1)$ & $-0.2271(3)$ & $0.0326(8)$ & $0.047(3)$ & $0.028(2)$ & $0.005(1)$ & $0.015(1)$ & $0.002(2)$ \\
\hline$C(4)$ & $4 e$ & $-0.2434(2)$ & $-0.1569(1)$ & $-0.2069(3)$ & $0.0394(9)$ & $0.022(2)$ & $0.022(2)$ & $0.005(1)$ & $0.0158(9)$ & $-0.007(2)$ \\
\hline$C(5)$ & $4 e$ & $-0.5095(2)$ & $-0.1575(1)$ & $-0.1017(2)$ & $0.0314(8)$ & $0.022(3)$ & $0.015(2)$ & $-0.004(1)$ & $0.0106(9)$ & $-0.002(2)$ \\
\hline$C(6)$ & $4 e$ & $-0.5543(3)$ & $-0.2181(2)$ & $-0.1559(3)$ & $0.048(1)$ & $0.032(3)$ & $0.044(2)$ & $-0.010(1)$ & $0.021(1)$ & $-0.009(2)$ \\
\hline$C(7)$ & $4 e$ & $-0.6839(3)$ & $-0.2524(1)$ & $-0.1092(3)$ & $0.061(1)$ & $0.037(3)$ & $0.047(3)$ & $-0.024(1)$ & $0.027(1)$ & $-0.027(2)$ \\
\hline$C(8)$ & $4 e$ & $-0.7651(3)$ & $-0.2257(1)$ & $-0.0130(3)$ & $0.043(1)$ & $0.026(3)$ & $0.038(2)$ & $-0.008(1)$ & $0.015(1)$ & $0.001(2)$ \\
\hline$C(9)$ & $4 e$ & $-0.7195(2)$ & $-0.1639(2)$ & $0.0392(3)$ & $0.0385(9)$ & $0.042(3)$ & $0.030(2)$ & $0.006(1)$ & $0.018(1)$ & $0.003(2)$ \\
\hline$C(10)$ & $4 e$ & $-0.5901(2)$ & $-0.1293(1)$ & $-0.0059(3)$ & $0.0380(9)$ & $0.030(2)$ & $0.026(2)$ & $-0.005(1)$ & $0.011(1)$ & $-0.012(2)$ \\
\hline
\end{tabular}

Acknowledgment. We would like to thank the Secretary of State for Scientific Research and Technology for financial support.

\section{References}

1. Albrecht, A. S.; Landee, C. P.; Tumbull, M. M.: Structure of bis(2-amino5-methylpyridinium) tetrachlorozincate at 298 and $150 \mathrm{~K}$. J. Chem. Crystallogr. 33 (2003) 269-276.

2. Li, Z. J.; Chen, X. M.; Ren, Z. X.; Li, Y.; Chen, X. A.; Huang, Z. T.: Crystal and molecular structure of hexahydro-2-(nitro-benzolmethylene)pyrimidine. Chin. J. Struct. Chem. 16 (1997) 311-314.

3. Soetofte, I.; Nielsen, K.: Benzotriazole complexes. I. The crystal structures of benzotriazolium tetrachlorocobaltate(II), bis(benzotriazole)dichlorozinc(II) and polymeric tetrakis(benzotriazolato)dizinc(II). Acta Chem. Scand. A35 (1981) 739-745.
4. Altomare, A.; Cascarano, M.; Giacovazzo, G.; Guagliardi, A.; Burla, M. C.; Polidori, G.; Camalli, M.: SIR92 - a program for automatic solution of crystal structures by direct methods. J. Appl. Crystallogr. 27 (1994) 435.

5. Molecular Structure Corporation: teXsan. Single Crystal Structure Analysis Software. Version 1.03. MSC, The Woodlands, Texas, USA 1997. 